\title{
A CASE REPORT: PANCREATIC NEUROENDOCRINE TUMOR
}

\section{A. A. Ghasura' ${ }^{1}$ K. H. Patel2 ${ }^{2}$, B. B. Prajapati ${ }^{3}$, Hitesh Mahida ${ }^{4}$, Manthan R. Merja ${ }^{5}$}

\section{HOW TO CITE THIS ARTICLE:}

A. A. Ghasura, K. H. Patel, B. B. Prajapati, Hitesh Mahida, Manthan R. Merja. "A Case Report: Pancreatic Neuroendocrine Tumor:". Journal of Evolution of Medical and Dental Sciences 2014; Vol. 3, Issue 22, June 02; Page: 6209-6216, DOI: 10.14260/jemds/2014/2724

ABSTRACT: Pancreatic neuroendocrine tumor (PNET) has an incidence of one per 100, 000 individuals per year. They represent about $1-2 \%$ of all pancreatic tumors. Non-functional PNET (NFPNET) are incidentally discovered in most cases. This article presents a review of NF-PNET and the case of a patient with this disease, in addition to its diagnosis, clinical presentation, and treatment.

KEYWORDS: Pancreas, Functional and Non-functional Pancreatic neuroendocrine tumors.

CASE REPORT: A 47 yr. old lady residing in Ahmedabad with low socioeconomic background presented with chief complains of mild dull aching continuous pain in epigastrium and RHC which often aggravated on fatty food along with few episodes of yellowish food containing vomiting after meals in last 30 days. She also had complains of decreased appetite and apparent loss of weight with no other gynecological complains. On examination mild tenderness was present in epigastrium and RHC with vaguely palpable mass in supra umbilical region. Routine blood investigations were done and found to be normal.

On USG (abdomen and pelvis) a pancreatic mass was found in head region. CECT abdo-pelvis clinched the diagnosis to be a well-defined soft tissue mass lesion in posterior part of head and uncinate process of $6.5 \times 6.3 \times 9 \mathrm{~cm}$ size with moderate enhancement on arterial and venous phase with non-enhancing necrotic areas within which was supplied by superior mesenteric artery and drained in superior mesenteric vein.

USG (abdo-pelvis): a pancreatic mass was found in head region.

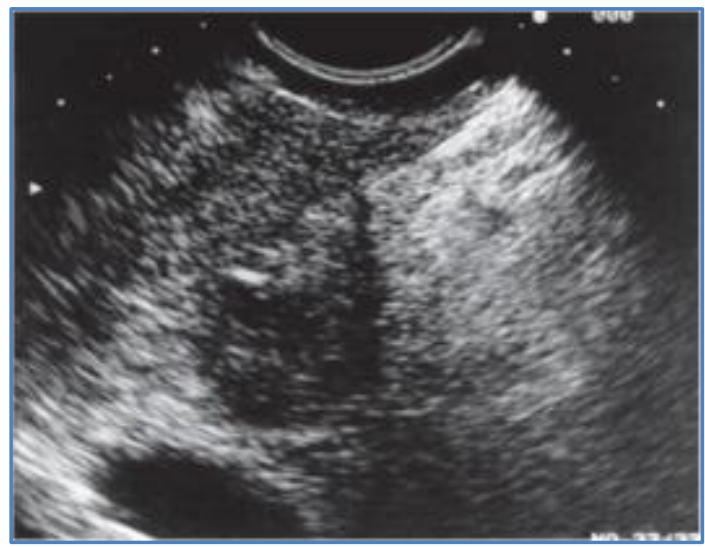

Fig. 1: EUS showing pancreatic neuroendocrine tumor mass 


\section{CASE REPORT}

EUS guided FNAC and FNAB: a well differentiated NET with occasional mitosis and marked nuclear anaplasia without any evidence of necrosis.

EUS-guided fine needle aspiration. The echo endoscope is positioned to image through the postero-inferior surface of the duodenal bulb.

CECT abdo-Pelvis: a well-defined soft tissue mass lesion in posterior part of head and uncinate process of $6.5 \times 6.3 \times 9 \mathrm{~cm}$ size.

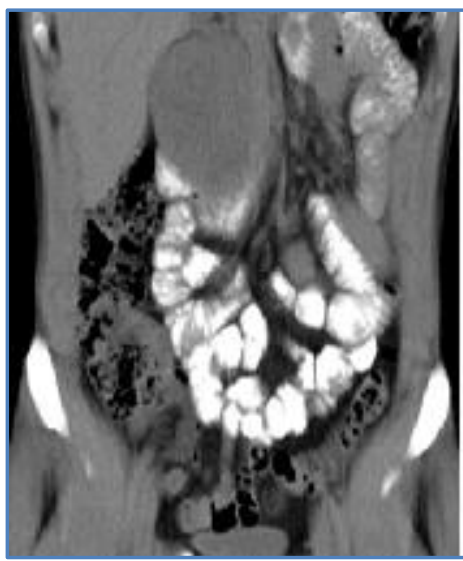

Figure 2

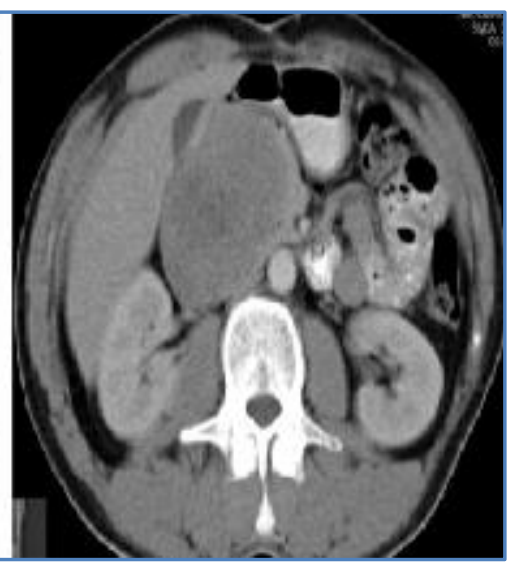

Figure 3

Fig. 2 \& 3: CECT ABDO-PELVIS showing well define fPNET mass in head and uncinate process

Fluid Amylase: $51885 \mathrm{U} / \mathrm{L}$

Fluid Lipase :> $120000 \mathrm{U} / \mathrm{L}$

Serum CA 19-9:8.8 U/ml (ref range 0-30.9)

Serum Fasting Insulin: $7.09 \mathrm{microU} / \mathrm{ml}$ (normal range 2.6-7.6)

RBS: $83.3 \mathrm{mg} / \mathrm{dl}$ (N 70-115).

S. Potassium: $3.6 \mathrm{mEq} / \mathrm{L}$ (N 3.5 - 5.6)

After routine workup tumor mass excision with cholecystectomy was performed on 4 the day of admission.

IHC: Synaptophysin and Cytokeratin.

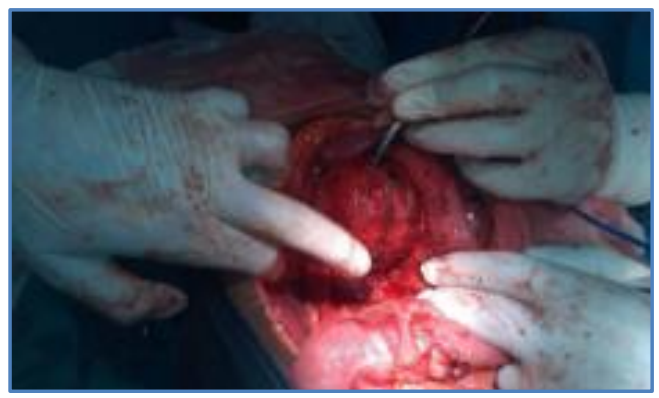

Figure 4 


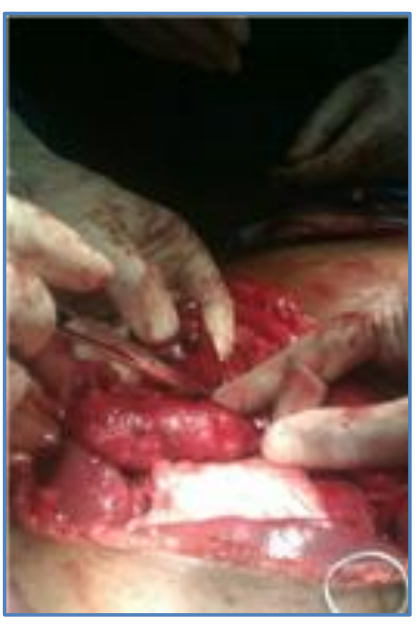

Figure 5

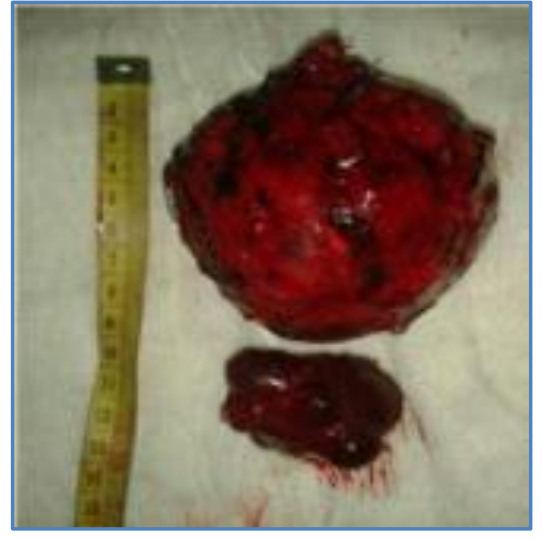

Figure 6

Fig. 4, 5 \& 6: Showing PNET mass clearly visible (shown by forcep) and size of the excided tumor mass.

\section{HPE:}

- Well differentiated neuroendocrine tumor $(12 \times 8 \times 5 \mathrm{~cm})$ of Pancreas

- Intermediate grade II tumor with intact capsule

- $\quad$ Mitosis of $3 / 10 \mathrm{hpf}$

- Ki index 3\%.

- Tumor necrosis - absent

- Lymphovascular invasion-present.

- Lymph node metastasis- present.

- GB - changes of active cholecystitis.

- Tumor stage was pT2 pN1.

Positive with Ki-67 index 3\%.

Post-operative patient developed some bouts of vomiting and abdominal pain which were managed conservatively. Drain was removed on post-operative day $18^{\text {th }}$ and patient was discharged. Patient came to CHA after 2 months with complains of abdominal pain colicky in nature acute in onset and in periumbillical region. Pain is associated with vomiting having gastric content. Routine blood investigations were within normal limits. USG abdomen was found to be normal. CECT abdomen and pelvis was done and report suggestive of calculus in cystic duct with changes of inflammation in cystic duct and CBD. Patient was managed conservatively and discharged.

On follow up patient was asymptomatic with a considerable weight gain and amylase lipase turned out to be within normal. 


\section{CASE REPORT}

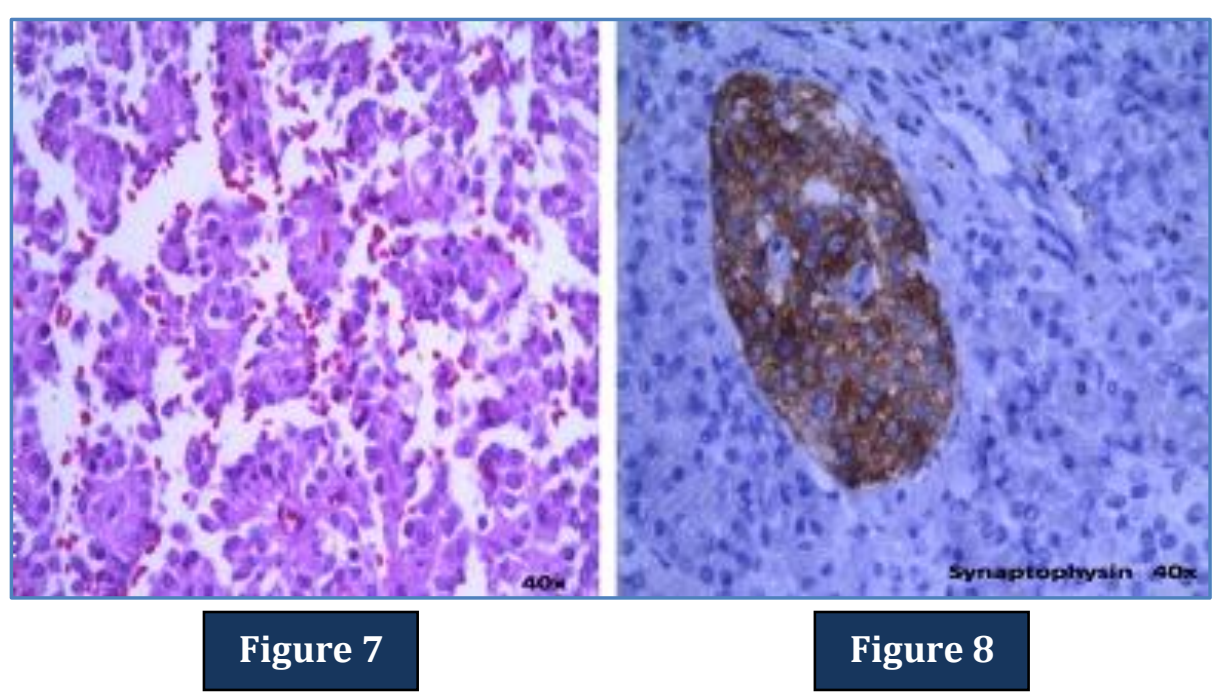

Fig. 7 \& 8: Showing immunohistochemistry: H \& E staining and Synaptophysin positive staining respectively.

DISCUSSION: Pancreatic neuroendocrine tumors (PNET) also known as islet cell carcinoma originates from neural crest cells also referred to as Amine Precursor Uptake and Decarboxylation cells (APUD). They constitute of Functional and Non-functional (NF) PNET. $(1,2,3)$

\section{Functional PNET:}

$>\quad$ Gastrinomas (Zollinger Ellison Syndrome Type II): It presents with gastric ulcers or eosophagitis. There is increased basal gastric acid secretion and elevated basal S. gastrin (normal $<100$ ). Secretin stimulation test helps to reach diagnosis. A combination of Octretide Scintigraphy and EUS is diagnostic. ${ }^{1,2,3}$

Typically present in Passaro's Triangle: - Junction of Cystic duct \& CBD, $2^{\text {nd }} \& 3^{\text {rd }}$ part of duodenum, neck $\&$ body of pancreas. ${ }^{1,2,3}$

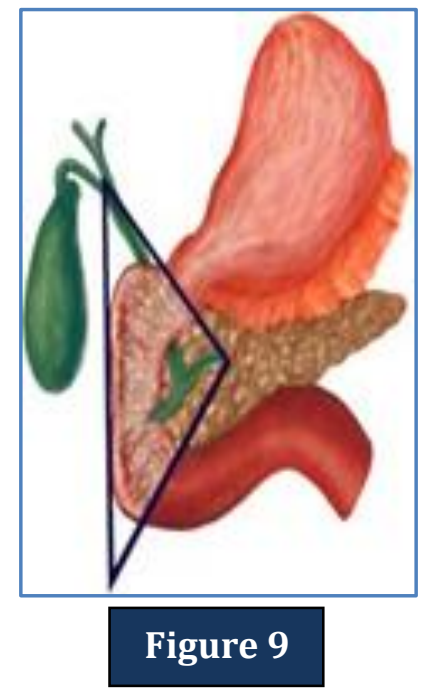

Fig. 9: Passaro's triangle 
MANAGEMENT: For non-metastatic lesion, surgical resection is done. For multiple and disseminated disease, human somatostatin analogue (octreotide), PPIs or $\mathrm{H}_{2}$ receptor blockers \& chemotherapy is necessary. ${ }^{1}$

> Insulinomas: The most common PNET. It is characterised by Whipple's Triad ${ }^{3}$ :

- Fasting hypoglycaemia

- $\mathrm{RBS}<50 \mathrm{mg} / \mathrm{dl}$

- Symptoms relieved on intake of glucose.

On blood examination one can find high plasma or Serum insulin together with high serum cpeptide. Surgery is the main treatment. Chemotherapy is used for metastatic disease. ${ }^{3}$

> VIPoma: It is vasoactive intestinal peptide secreting tumors occur as WDHA syndrome: Watery Diarrhoea, Hypokalaemia and Achlorhydria. There is increased plasma VIP concentration (Normal $<75 \mathrm{pg} / \mathrm{ml}$ ). Surgical excision is curative in many cases. . $, 2,3^{2}$

D Glucagonoma: Characterized by 4Ds: diabetes, dermatitis, depression and deep vein thrombosis. It is usually malignant. Tests that are useful are CT scan, S.Glucose, S. Glucagon. Surgery is treatment of choice. ${ }^{3}$

\section{Non-functional PNET:}

After Insulinomas however NF PNET are the most common entities. No any functional hormone secreted. Patient presents in late stage when tumor shows symptoms due to compression or metastasis. Stains positive with Pancreatic Peptide usually. ${ }^{1}$

Genetic risk factors for PNET: Mutations of NETS, MEN1, ATRX, DAXX, TCS2, PTEN andPIK3CA genes. ATRX, DAXX and MEN1 mutations have better prognosis. ${ }^{4}$

\section{Thus PNET are seen several familial syndromes including 5:}

- MEN1- multiple endocrine neoplasia 1

- VHL -von HIppel Lindau syndrome

- Neurofibromatosis type 1

- Tuberous Sclerosis

\section{Tumor markers for PNET 6:}

- Chromaogranin A

- Beta HCG

- Neuron specific enolase

A higher than normal amount of Chromagranin A and normal amount of hormones such as gastrin, insulin and glucagon can be a sign of NF-PNET. 6 


\section{CASE REPORT}

Imaging techniques for pancreatic tumors:

- CECT SCAN: Imaging technique of choice in PNET.

- PET SCAN: Helps distinguish chronic pancreatitis from pancreatic Ca.

- OCTREOSCAN: Helps in small pancreatic mass, especially Gastrinomas. Here radioactive octreotide is used as a marker.

- EUS: More useful in case of symptomatic tumors of $<1 \mathrm{~cm}$ in size.

Diagnostic Laparoscopy: Along with intraoperative US it can predict the resectability of tumor upto $98 \%$.

Immunohistochemistry: Positive staining with chromogranin A and synaptophysin confirms the diagnosis and these are elevated in $60-100 \%$ of NF-PNETs.

\section{MANAGEMENT OF PNET ${ }^{6,7,8}$}

\section{SURGERY:}

- ENUCLEATION: removes tumor only

- PANCREATODUODENECTOMY: Also called WHIPPLE'S PROCEDURE.

- DISTAL PANCREATECTOMY: removes head and tail of pancreas and sometimes spleen

- PARIETAL CELL VAGOTOMY: for unresectable Gastrinomas.

- LIVER RESECTION for liver metastases.

- INTRAOPERATIVE RADIOABLATION: A special probe with tiny electrodes inserted into tumor mass.

- INTRAOPERATIVE CRYOABLATION: Uses liquid Nitrogen or CO2 during Laparotomy or Laparoscopy.

HORMONE THERAPY: It is useful in unresectable cases. Monthly injections of Octreotide are useful.

RADIOTHERAPY: To control metastases related symptoms of pain, eg. Bone metastasis.

\section{CHEMOTHERAPY:}

- In undifferentiated tumor cells.

- Chemotherapy regimen with doxorubicin, 5-FU and streptozocin has significant activity in patients with locally advanced and metastatic PNET.

PPRT: Peptide Receptor Radionuclide Therapy uses Somatostatin conjugated with radioactive agents like Indinium-111 or Yttrium-90 o target the tumor cells that have higher affinity for Somatostatin.

HEPATIC ARTERY TREATMENT: Used to treat hepatic metastasis. Tumor cells are wholly dependent on hepatic artery for nutrition, while the normal cells get $70-80 \%$ nutrients and $50 \% 02$ from Portal vein: 8

- HEPATIC ARTERY EMBOLIZATION: Occludes the blood flow to tumor.

- HEPATIC ARTERY CHEMOTHERAPY: Higher proportion of chemotherapy agents delivered to lesion in liver. 
- HEPATIC ARTERY CHEMOEMBOLIZATION: Also called Trans Arterial Chemo Embolization (TACE). Embospheres bound with chemotherapy agents injected into hepatic artery.

- SELECTIVE INTERNAL RADIATION THERAPY: Also called Radioactive Microspheres Therapy (RMT) injects radiolabelled microspheres into the hepatic artery.

FOLLOW UP: Tumor have tendency to recur in pancreas or in other parts of the body. So regular follow-up is essential.

CONCLUSION: There is need for new management guidelines for patients with these characteristics that can help to make good decisions. The characteristics of this pathology and its presentation and the differential diagnoses should be kept in mind while treating any pancreatic mass.

ABBREVIATIONS: CECT- Contrast Enhanced Computed Tomography, USG- Ultrasonography, RHCRight hypochondrium, CHA- Civil Hospital Ahmedabad, EUS- Endoscopic Ultrasonography, FNACFine Needle Aspiration Cytology, CBD- Common Bile Duct.

\section{REFERENCES:}

1. William E. Fisher, Dana K. Anderson, Richard H. Bell Jr, Ashok K. Saluj\& F. Charles Brunicardi. Schwartz's principles of surgery 9thedi. Chap-33, p 1217-1236. Book.

2. Taylor S. Riall, B. Mark Evers. Maingot's abdominal operations. 12th edi. P 1211-1232. Book.

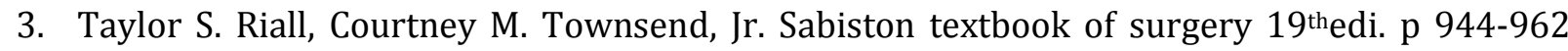
(Book).

4. Yuchen Jiao, Chanjuan Shi, Barish H. Edil, Roeland F. de Wilde, David S. Klimstra, Anirban Maitra et al. DAXX/ATRX, MEN1, and mTOR Pathway Genes Are Frequently Altered in Pancreatic Neuroendocrine Tumors.(Report)January 202011 Science 4 March 2011: Vol. 331 no. 6021 pp. 1199-120. From http://www.sciencemag.org/content/331/6021/1199.short.

5. Tetsuhide Ito, Hisato Igarashi and Robert T. Jensen. Pancreatic neuroendocrine tumors: clinical features, diagnosis and medical treatment: advances.

From http://www.ncbi.nlm.nih.gov/pmc/articles/PMC3627221/.

6. David C. Metz, Robert T. Jensen. Gastrointestinal Neuroendocrine Tumors: Pancreatic Endocrine Tumors. From: http://www.gastrojournal.org/article/S0016-5085\%2808\%2900868-8/fulltext\#sec4

7. François Pattou, Charles Proye. Endocrine tumors of the pancreas. Available from: http://www.ncbi.nlm.nih.gov/books/NBK6889/

8. Ingemar Ihse, Gert Lindell, Sten Tibblin. Neuroendocrine tumors metastatic to the liver. Available from:http://www.ncbi.nlm.nih.gov/books/NBK6993/\#A3808. 


\section{CASE REPORT}

\section{AUTHORS:}

1. A. A. Ghasura

2. K. H. Patel

3. B. B. Prajapati

4. Hitesh Mahida

5. Manthan R. Merja

\section{PARTICULARS OF CONTRIBUTORS:}

1. Professor, Department General Surgery, Civil Hospital, Ahmedabad.

2. Assistant Professor, Department of General Surgery, Civil Hospital, Ahmedabad.

3. Assistant Professor, Department of General Surgery, Civil Hospital, Ahmedabad.

4. Junior Resident, Department of General Surgery, Civil Hospital, Ahmedabad.
5. Junior Resident, Department of General Surgery, Civil Hospital, Ahmedabad.

\section{NAME ADDRESS EMAIL ID OF THE CORRESPONDING AUTHOR:}

Dr. Manthan R. Merja, Room No. 18, D-8 Wing,

Civil Hospital,

Asarwa, Ahmedabad.

Email: mrmerja@gmail.com

Date of Submission: 08/05/2014.

Date of Peer Review: 09/05/2014.

Date of Acceptance: 17/05/2014.

Date of Publishing: 02/06/2014. 